\title{
MERAWAT LANSIA DENGAN GANGGUAN MOBILISASI MEMBENTUK NILAI SPIRITUAL DAN KULTURAL ANGGOTA KELUARGA DI SRENGSENG SAWAH, JAKARTA SELATAN
}

\section{CARING FOR MOBILITY- IMPAIRED ELDERS ENHANCES SPIRITUAL AND CULTURAL VALUES OF FAMILY MEMBERS IN SRENGSENG SAWAH SOUTH JAKARTA}

\author{
Ratna Lestari ${ }^{1{ }^{*}}$, Etty Rekawati ${ }^{2}$, Wiwin Wiarsih ${ }^{3}$ \\ *1Program Studi Keperawatan Fakultas Kesehatan Universitas Jenderal Achmad Yani Yogyakarta, J. \\ Brawijaya Ringroad Barat, Ambarketawang, Gamping, Sleman, D.I.Yogyakarta 55294, \\ Email:Iestariratna_86@yahoo.com, Indonesia \\ ${ }^{2}$ Staf Pengajar Magister dan Spesialis Keperawatan Fakultas IImu Keperawatan Universitas Indonesia, \\ Depok, 16424, Indonesia \\ ${ }^{3}$ Staf Pengajar Magister dan Spesialis Keperawatan Fakultas IImu Keperawatan Universitas Indonesia, \\ Depok, 16424, Indonesia
}

\begin{abstract}
Background: Mobility impairment is a chronic disease that needs long-term care. This condition will change many aspects of elders' life that are difficult to adapt. Family members who act as a caregiver are the essential part of elders' life.

Objective: This study aimed to explore the meaning of caregiving for elders with mobility impairment by family members.

Methods: In-depth interviews were conducted with eight family caregivers who were taking care for mobilityimpaired elders. In this phenomenological qualitative study, data were then analyzed with content analysis by Colaizzi method.

Results: The essence of elderly caregiving for family was to grow both spiritual and cultural values in their lives. Looking for the Lord's blessing; life's tests; looking for the Lord's fortune; and God's training for patience were included in the spiritual value while the cultural values consisted of child obligation; responsibility; future expectation; role model for children; and filial piety.

Conclusion: Obstacles faced by family caregivers can be overcome by taking the essence of caregiving as part of spiritual and cultural values thus caring can be provided continuously and compassionately. The findings recommended the cultural aspects in caring elderly need to be investigated further using ethnography approach.
\end{abstract}

Keywords : Cultural Values, Elderly, Family Caregiver, Mobility Impairment, Spiritual Values

\section{PENDAHULUAN}

Peningkatan Usia Harapan Hidup (UHH) berbanding lurus dengan peningkatan jumlah penduduk berusia di atas 60 tahun atau lansia. Peningkatan UHH menjadi tantangan pembangunan berkaitan dengan masalah kesehatan lansia, salah satunya penyakit persendian. ${ }^{1}$ Prevalensi penyakit persendian mengalami penurunan sebesar $5,6 \%$ tahun 2013 yaitu sebesar $24,7 \%{ }^{2}$
Selaras dengan prevalensi di Indonesia, prevalensi penyakit sendi di DKI Jakarta tahun 2007 sebesar 29,3\%. Penurunan prevalensi juga terjadi pada tahun 2013 sebesar $7,5 \%$ menjadi $21,8 \%{ }^{2}$ Penurunan prevalensi penyakit persendian tidak serta merta menghilangkan dampak yang ditimbulkan sepertketerbatasan pergerakan terutama pada usia yang semakin tua. 
Keterbatasan pergerakan dan berkurangnya pemakaian sendi memperburuk kondisi lansia yang berakibat pada gangguan mobilisasi. Gangguan mobilisasi merupakan suatu kondisi terbatasnya pergerakan pada fungsi salah satu atau lebih ekstremitas tubuh. ${ }^{3}$ Gangguan mobilisasi memengaruhi kemandirian karena ketergantungan lansia dalam melakukan aktivitas sehari-hari yang seharusnya masih bisa dilakukan oleh lansia.

Gangguan mobilisasi tidak hanya mengubah kemandirian lansia secara fisik, namun respon psikologis juga mengalami perubahan. Kehilangan kemandirian akibat gangguan kesehatan dapat menyebabkan putus asa, menarik diri dan isolasi sosial yang dapat mengganggu hubungan interpersonal. $^{4}$

Lansia dengan gangguan mobilisasi merupakan kelompok rentan yang membutuhkan bantuan tenaga profesional atau non profesional di luar keluarga maupun anggota keluarga sebagai sumber perawatan kesehatan. Pemberian perawatan kesehatan oleh keluarga mengacu pada aktivitas yang diberikan oleh anggota keluarga seperti suami, istri, anak, menantu kepada lansia sehingga peran dan tanggung jawab memberikan perawatan bertumpu pada mereka. $^{5}$

Perawatan yang diberikan keluarga kepada lansia menumbuhkan nilai-nilai positif dalam kehidupan seperti nilai spiritual dan nilai budaya. ${ }^{6,7}$ Nilai ini saling berdampingan karena adanya budaya berakar dari nilai spiritual. Spiritualitas berkaitan erat dengan pemahaman akan arti dan tujuan hidup manusia, dalam konteks ini berkaitan dengan perawatan yang diberikan kepada lansia dengan gangguan mobilisasi.

Tingkat spiritualitas seorang individu dimaknai sebagai tingkatan tertinggi sebagai seorang manusia karena arti dan tujuan hidupnya berlandaskan pada kepercayaannya kepada Tuhan Yang Maha Esa. ${ }^{8,9}$ Penelitian sebelumnya menggambarkan makna dari merawat lansia sebagai ibadah dan cobaan ujian dari Tuhan yang merupakan wujud rasa sayang Tuhan kepada hamba-Nya agar selalu mengingatNya. ${ }^{10,11}$

Selain bernilai secara spiritual, merawat lansia diyakini sebagai bentuk budaya masyarakat ketimuran. Budaya Indonesia memegang teguh nilai dan keyakinan tentang rasa berbakti pada orang tua yang diwujudkan dengan merawat lansia dengan gangguan mobilisasi

sehingga ketergantungan dalam pemenuhan kebutuhan sehari-hari dibantu oleh anggota keluarga lain. Merawat lansia merupakan kewajiban anak dan menantu sebagai ciri budaya masyarakat Indonesia yang masih mengutamakan keluarga sebagai pelaku rawat. $^{12}$

Nilai spiritual dan budaya yang tumbuh pada anggota keluarga membutuhkan penggalian lebih mendalam sehingga akan didapatkan perspektif nilai-nilai tersebut 
berdasarkan pengalaman keluarga sememberikan perawatan pada lansia dengan gangguan mobilisasi.

\section{BAHAN DAN CARA PENELITIAN}

Metode yang digunakan dalam penelitian ini adalah studi kualitatif dengan desain fenomenologi deskriptif. Studi fenomenologi deskriptif digunakan karena lebih fokus menggambarkan pengalaman partisipan dan tidak menggunakan penafsiran peneliti, sehingga perspektif baru dirasakan oleh peneliti. ${ }^{13}$ Penelitian fenomenologi deskriptif ini melibatkan 8 orang pelaku rawat utama berasal dari keluarga yang dipilih dengan teknik purposive sampling di wilayah kerja Puskesmas Jagakarsa Jakarta Selatan. Partisipan terdiri atas pelaku rawat utama yang membantu memenuhi kebutuhan lansia dengan gangguan mobilisasi, tinggal bersama atau berdekatan dengan lansia, dan mampu menceritakan dengan lancar pengalamannya selama merawat lansia.

Penelitian ini telah mendapatkan izin etik dari komite etik Fakultas IImu Keperawatan Universitas Indonesia. Nama partisipan sudah diganti dengan kode yang tidak dapat teridentifikasi. Semua partisipan menandatangani lembar persetujuan dan dapat sewaktu-waktu mengundurkan diri dari penelitian tanpa pemberian sangsi apapun.

Wawancara mendalam (indepth interview) dan semi terstruktur dipilih sebagai metode pengumpulan data, urutan pertanyaan yang diajukan pada tiap partisipan tidak sama dan bergantung pada jawaban tiap individu namun tetap sesuai dengan pedoman wawancara. Proses wawancara berakhir apabila informasi yang dibutuhkan telah diperoleh sesuai tujuan penelitian, rerata waktu yang dibutuhkan untuk wawancara selama 60 menit.

Peneliti menerapkan prinsip bracketing selama melakukan analisis data sehingga kategori, sub tema dan tema yang didapat berasal dari pernyataan signifikan partisipan dan tidak melibatkan konsep teori yang berkaitan. Proses analisis data dilakukan secara bersamaan dengan proses pengumpulan data, segera setelah peneliti selesai melakukan wawancara peneliti langsung membuat transkrip percakapan. Peneliti menggunakan metode Collaizi sebagai analisis data, karena peneliti dapat melakukan klarifikasi kembali kepada partisipan untuk melengkapi analisis.

\section{HASIL DAN PEMBAHASAN}

Nilai-nilai spiritual dan kultural sebagai makna merawat lansia merupakan hasil yang muncul dari penelitian ini.

\section{Nilai spiritual}

Nilai spiritual merupakan hal yang penting tertanam dalam kehidupan manusia, nilai spiritual akan menjadikan manusia menjadi lebih memaknai apa yang dilakukannya untuk orang lain. Nilai spiritual merupakan nilai tertinggi dan mutlak karena bersumber pada Tuhan Yang Maha Esa dan digunakan sebagai kendali dalam memilih 
kehidupan yang baik. Nilai spiritual selama merawat tergambar melalui beberapa kategori di bawah ini, yaitu:

Mencari rida Tuhan sebagaimana tergambar melalui ungkapan partisipan berikut ini:

'Nyari rida Allah gitu dengan ngurusin suami, saya dijadiin ladang amal ladang ibadah " (P8)

Nilai spiritual juga terlihat dari pernyataan partisipan yang menyatakan dengan merawat lansia maka rezeki akan didapatkan dari manapun, berikut ungkapannya:

“...kalo saya cari berkahnya aja, ngurusin orang tua kan berkah (dengan nada rendah dan santai), alhamdulilah rezeki ada aja entah dari mana-dari mana..." (P1)

"Ngerawat nenek biar berkah, biar dilancarin rezekinya supaya ada terus..." (P6)

Selain mendapatkan rezeki, merawat lansia juga dirasakan sebagai ujian dari Allah SWT sebagaimana ungkapan partisipan berikut ini:

“...kadang-kadang kita Ya Allah (sambil mengelus dada), ternyata Allah menguji saya, merawat orang sakit juga sebagai ujian, ini ujian saya (mata berkacakaca)..." (P3)

Nilai spiritual yang ditimbulkan selama merawat lansia adalah sebagai pembelajaran untuk melatih kesabaran, seperti ungkapan partisipan berikut ini:

"Alhamdulilah setelah ngurusin ibu yang lumayan lama, jadi lebih sabar dan terbiasa, jujur saya orangnya gak sabaran, pemarah sekarang jauh jauh lebih sabar..." (P5)

"Kadang-kadang kita dilatih untuk sabar, ekstra sabar, menahan amarah" (P2).

\section{Nilai budaya}

Merawat lansia dengan gangguan mobilisasi merupakan perwujudan nilai budaya. Budaya berakar dari spiritual sehingga berdampingan dan tidak bisa terlepas dalam menjalankannya. Nilai budaya diidentifikasi melalui beberapa kategori yang diuraikan berikut ini:

Kewajiban anak, sebagaimana ungkapan partisipan:

"...kewajiban merawat orang tua itu bagi semua anak, sekarang orang tua saya tidak mampu melakukan aktivitas seperti biasa, saya berkewajiban merawat" (P3) "...baba bilang terima kasih sama kita yang merawat, tapi kita bilang udah kewajiban anak ngurus orang tua, satu hal penting kewajiban anak terhadap orang tua..." (P2)

Partisipan berharap ketika merawat orang tua saat ini akan memperoleh hal yang sama ketika hari tua yaitu dirawat oleh anak. Berikut pernyataan partisipan:

"Kita sebagai anak, harus mikir besok kita akan tua juga insyaAllah juga dirawatin sama anak" (P1)

“...barangkali saya akan tua, ketika kita nggak mampu merawat diri kita sendiri mungkin anak saya yang ngerawatin saya, nantinya kita juga akan mendapatkan yang kita tanam" (P3)

Merawat lansia sebagai suatu bentuk tanggung jawab yang harus dijalankan baik yang ditinjau melalui beberapa hal yaitu posisi anak di dalam keluarga, hubungan dengan lansia dan menggantikan posisi 
suami dalam merawat lansia. Berikut merupakan ungkapan tiga orang partisipan:

'Istilahnya aku anak perempuan pertama di keluarga, jadi saya merasa terpanggil untuk ngerawatin ibu" (P3)

“...kita tetep ngurusin ibu dari pada gak ada yang ngurusin kan udah tanggung jawab sebagai menantu" (P4)

Penanaman budaya sangat penting bagi generasi penerus agar memiliki kepedulian terhadap orang lain terutama lansia sehingga akan memunculkan rasa berbakti pada orang tua melalui pemberian perawatan. Berikut ungkapan salah satu orang partisipan:

"Bisa kasih tau anak-anak nantinya cara berbakti sama orang tua, salah satunya ngerawatin baba" (P2)

Satu orang partisipan menyampaikan bahwa merawat lansia mempunyai makna sebagai balas jasa atas apa yang dilakukan lansia pada orang tuanya yang saat ini sudah tiada sehingga merawat lansia dilanjutkan oleh seorang cucu kepada neneknya. Berikut ungkapan partisipan :

"Aku pikir kalo gak ngerawat nenek siapa lagi, dulu kan mamah diurusin sama nenek sekarang bales yang dilakuin sama nenek ke mamah dulu" (P6).

\section{PEMBAHASAN}

Spiritual secara umum mengacu pada kecenderungan seseorang untuk menentukan arti dan tujuan hidup, kedamaian dalam diri dan penerimaan, memaafkan, harmoni dan harapan. ${ }^{9}$
Penelitian ini mendapatkan nilai spiritual yang ditimbulkan selama merawat lansia berupa mencari rida Tuhan, mencari berkah, ujian dan melatih kesabaran. Rida Tuhan mempercayai sesungguh-sungguhnya bahwa apa yang menimpa kepada kita, baik suka maupun duka adalah terbaik menurut Tuhan. Tuhan telah menggariskan pada hambaNya sesuatu yang berdampak baik bagi hambaNya, maka orang yang mengharapkan rida Tuhan mempercayai bahwa apa yang menimpanya adalah yang terbaik bagi dirinya sehingga tidak akan membenci kejadian yang terjadi padanya dengan lebih bersabar. Bahkan pada penelitian sebelumnya merawat anggota keluarga dimaknai sebagai peningkatan rasa syukur, sebagai berkah dan ibadah. $^{10,11}$

Nilai spiritual sangat penting bagi pelaku rawat karena dengan tumbuhnya nilai spiritual dapat meningkatkan efikasi diri, memiliki hubungan yang lebih dekat dengan Tuhan dan sumber kekuatan terbesar dalam mendukung kehidupan, meningkatkan optimisme dan koping adaptasi dalam mengatasi masalah yang dirasakan dalam hal ini merawat lansia. ${ }^{14}$ Nilai spiritual berkaitan dengan aspek positif yang membentuk kesejahteraan psikologis individu seperti kepuasan dalam memberikan perawatan yang dapat mengurangi beban selama memberikan perawatan sehingga berdampak pada kualitas perawatan yang diberikan kepada lansia. ${ }^{15}$ 
Peneliti menghubungkan karakteristik agama dengan keyakinan dalam agama Islam. Dalam perspektif muslim yang berpedoman pada ajaran agama Islam, selain QS. Al Isra 23-24 yang memerintahkan manusia untuk merawat orang tua yang sudah lanjut usia, QS. Luqman ayat 14 juga mengajak manusia untuk berbuat baik pada orang tuanya yang menyiratkan bahwa manusia hendaknya berbuat baik kepada orang tuanya karena jasa orang tua tidak dapat tergantikan oleh apapun dan rasa syukur tersebut tercermin melalui pemberian perawatan ketika orang tua sudah tidak mampu merawat dirinya sendiri.

Selain spiritual, merawat lansia juga menumbuhkan nilai budaya bagi anggota keluarga lainnya. Budaya di Indonesia menganggap perawatan yang diberikan pada lansia sebagai bentuk balas budi dan tanggung jawab. Hal ini dapat dikaitkan dengan karakteristik hubungan pelaku rawat dengan orang yang dirawat. Partisipan dalam penelitian ini memiliki hubungan sebagai istri, anak, menantu dan cucu yang mempunyai kedekatan secara ikatan darah. Temuan ini mendukung penelitian lain bahwa ikatan darah membentuk identifikasi yang kuat dan solidaritas antara individu dengan keluarganya sebagai perasaan yang kuat untuk mendedikasikan, membalas, patuh, berbakti dan dekat dengan anggota keluarganya. $^{12}$

Merawat anggota keluarga khususnya lansia dengan penyakit yang dideritanya bersumber pada nilai budaya yang tertanam dari keluarga baik pada masyarakat Indonesia maupun ras di dunia yang juga memiliki persamaan. Merawat lansia adalah hal alamiah yang tidak membutuhkan alasan untuk melakukannya, karena merupakan wujud berbakti, tanggung jawab dan kewajiban anak terhadap orang tua yang juga dipengaruhi oleh ikatan darah dalam keluarga sehingga membentuk hubungan yang dekat antara pemberi dan penerima perawatan.

\section{KESIMPULAN}

Pelaku rawat yang berasal dari keluarga memiliki peran penting dalam pemberian perawatan, karena ikatan antara pelaku rawat dengan pemberi perawatan dapat mempengaruhi perawatan yang diberikan. Selama memberikan perawatan dapat menumbuhkan nilai-nilai spiritual dan kultural yang merupakan makna merawat yang sesungguhnya sebagai wujud rasa berbakti, kewajiban anak dan lebih khusus berkaitan dengan kepercayaan manusia kepada Tuhan untuk mendapatkan tingkatan tertinggi secara spiritual yaitu mengharapkan ridho Tuhan sehingga bagaimana pun pengalaman yang dirasakan selama merawat, pelaku rawat mempercayai sesungguh-sungguhnya bahwa apa yang menimpa kepada dirinya, baik suka maupun duka adalah terbaik menurut Tuhan. Berdasarkan hasil penelitian disarankan agar dilakukan penelitian lebih mendalam tentang 
makna agama dan budaya dalam merawat lansia sesuai dengan karakteristik budaya lansia dan partisipan.

\section{TERIMA KASIH :}

1. Kuswanto Hardjo, dr., M.Kes, Dekan Fakultas Kesehatan Universitas Jenderal Achmad Yani Yogyakarta, email: info@unjaya.ac.id

2. Deby Zulkarnain Rahardian Syah, MMR, Ketua PPPM Universitas Jenderal Achmad Yani Yogyakarta, 0274 4342000, email: pppm@unjaya.ac.id

\section{KEPUSTAKAAN}

1. Kemenkes RI. Jendela data dan informasi lansia. Buletin Semester I ISSN 2088-207X; 2012. Jakarta: Kemenkes $\mathrm{RI}$.

2. Kemenkes RI. Riset Kesehatan Dasar (RISKESDAS); 2013. Jakarta: Badan Penelitian dan Pengembangan Kesehatan Kementerian Kesehatan Republik Indonesia.

3. Herdman, T.H., \& Kamitsuru, S. NANDA International Nursing Diagnoses: definition and classification 2015-2017. Oxford: Wiley Blackwell; 2014.

4. Creedon, R., \& Weather, E. The impact of osteoartritis on psychological wellbeing. British Journal of Nursing; 2011; Vol. 20 No 4.

5. Friedman, M.M., Bowden, V.R.,\& Jones, E.G. Family nursing: Research, theory, and practic. Edisi 5. Connecticut: Appleton \& Lange; 2003.

6. McClearly, L \& Blain, J. Cultural Values and Family Caregiving for Persons with Dementia. Indian Journal of Gerontology 2013; Vol. 27, No. 1, pp. 178-201

7. Pharr, J.R., Francis, C.D., Terry, C., \& Clark, M.C. Culture, Caregiving, and Health: Exploring the Influence of Culture on Caregivers Experiences. Public
Health ISRN. 2014; Vol. 2014. Article ID 689826

8. Lynn, B., Grace, J.Y., \& Levine, E.G. Trust in the Lord": Religious and Spiritual Practices of African American Breast Cancer Survivors. J Relig Health. 2014; Vol. 53:1706-1716

9. Bermand, A., Snyder, S., \& Frandsen, G. Kozier \& Erb's Fundamental of nursing: concepts, process, and practice. Edisi 10. New Jersey: Pearson; 2016.

10. Badriyah, S. Pengalaman keluarga merawat lansia dengan diabetes mellitus di Kota Tasikmalaya. Tesis tidak dipublikasikan; 2011.

11. Nugraha, N.J. Pengalaman keluarga merawat anggota keluarga yang menjalani terapi hemodialisis di Rumah Sakit. Tesis tidak dipublikasikan; 2012.

12. Sahar J, Courtney M, Edwards $H$. Improvement of family carers' knowledge, skills and attitudes in caring for older people following the implementation of a Family Carers' Training Program in the community in Indonesia. International Journal of Nursing Practice. 2003; Vol. 9: 246-254

13. Creswell, J.W. Qualitative Inquiry \& Research Design: choosing among five approaches. Edisi 3. Washington DC: Sage Publications, Inc; 2013.

14. Jeonghim, H.G. Religious Coping, Positive Aspects of Caregiving, and Social Support Among Alzheimer's Disease Caregivers. Clinical Gerontologist. Vol. 37:368-385; 2014.

15. Kruithof, W.J., Meily, J.M., \& Marcel, W.M. Positive Caregiving Experiences Are Associated with Life Satisfaction in Spouses of Stroke Survivors. Journal of Stroke and Cerebrovascular Diseases. 2012; Vol. 21, No. 8. 